BBA 66429

\title{
DETERMINATION OF ACYL-COA CONCENTRATIONS USING PANCREATIC LIPASE
}

EUGENE D BARBER AND WILLIAM E M LANDS

Department of Biological Chemistry, The University of Michigan, Ann Arbor, Mich ${ }_{4810+}(U S A)$

(Recerved June 8th, I97I)

\section{SUMMARY}

A rapid and sensitive assay for acyl-CoA thiol esters has been devised using pancreatic lipase as a hydrolytıc agent in the presence of dithionitrobenzoic acid to detect the liberated CoA Acyl thiol esters containing I2-22 carbon atoms and o-6 double bonds are measurable in this system whereas acetyl-CoA and malonyl-CoA were not cleaved

\section{INTRODUCTION}

Enzymes catalysing the hydrolysis of a variety of acyl thiol esters have been reported $^{1}$ Several have been implicated in exergonıc processes which help to drive the synthesis of other compounds ${ }^{2-4}$, but the biological function of most remains obscure $^{5,6}$

During the course of some experiments in which pancreatic lipase ${ }^{7}$ was added to acyltransferase reaction mixtures, we noted an acyl-CoA hydrolase activity associated with the lipase preparation The enzyme, in the presence of acyl-CoA and 5,5'-dithiobis-(2-nitrobenzoic acid) (DTNB), seems able to liberate free CoA as evidenced by an increase in the absorbance at $4 \mathrm{I} 3 \mathrm{~nm}$ (ref 8) We thought that the hydrolytic activity could be used as the basis for an assay to routinely measure acylCoA concentrations in various solutions The present communication describes the conditions and characteristics of this assay system

METHODS

\section{Reagents}

Pancreatıc lipase, 30 units/mg, was purchased from Worthington Tris was a product of Sigma Chemical Company and DTNB was obtained from Aldrich Chemical Company "Pancreatin" was purchased from Viobin Corporation

Abbreviation DTNB, 5,5'-dithiobis-(2-nitrobenzoic acid) 


\section{Enzyme solutions}

Enzyme solutions (20 mg/ml) were prepared in o I M Tris-HCl buffer ( $\mathrm{pH} ; 4)$ and stored at - $\mathrm{IO}^{\circ}$ DTNB was dissolved in delonized water, (titrated to $\mathrm{pH}_{4}$ with $\mathrm{NaOH})$ and stored at $4^{-} \mathrm{Acy}$ 1-CoA derivatives were prepared from the corresponding acid chlorides by the method of SEUBERT ${ }^{9}$ and stored at $-10^{\circ}$ Santoquin, a gift of Monsanto Chem $\mathrm{C}_{0}$, was added to unsaturated acyl-CoA solutions as an antioxidant Phosphate analyses were performed on acid hydrolysates of acyl-CoA solutions as described by EIBL AND LANDs ${ }^{10}$

\section{Spectrophotometric measurements}

These measurements were performed using a Gilford Model 2000 recording spectrophotometer at ambient temperature Cuvettes of $\mathrm{I} \mathrm{cm}$ pathlength were used throughout The extinction coefficient for free TNB was taken to be $13600 \mathrm{M}^{-1} \mathrm{~cm}^{-1}$ at 4 I $3 \mathrm{~nm}$ (ref 8)

\section{Standard assay system}

The standard assay contained $90 \mu$ moles of Tris- $\mathrm{HCl}$ buffer $(\mathrm{pH} 74)$, Io $\mu$ moles of DTNB and o I-I o $\mathrm{mg}$ pancreatic lipase in a total volume of $\mathrm{I}$ o $\mathrm{ml}$

RESULTS

Properties of the assay system

Fig I shows the spectrophotometric traces obtained when various amounts of acyl-CoA were added to the standard assay system The absorbance at $4 \mathrm{I} 3 \mathrm{~nm}$ ncreased rapidly after acyl-CoA was added (Point $\mathrm{A}$ ) and the absorbance at the endpoint was proportional to the amount of acyl-CoA added Subsequent additions of acyl-CoA (Point B) led to further proportional increases in the absorbance, indicating that the hydrolase activity remained functional during the course of the assar The very slow increase in absorbance seen in the case of Cuvette I might have been due to the reaction of exposed protein sulfhydryl groups with DTNB as the protein slowly unfolds Addition of sodium deoxvcholate $\left(005_{0}^{\circ}(\mathrm{w} / \mathrm{v})\right.$ final concentration) did not increase the rate seen in Cuvette I No increase in absorbance was detected when the enzyme was omitted or when enzyme which had been heated at $100^{\circ}$ for 15 min was added "Pancreatın", an acetone powder of whole pancreas, was also active in the assay system, although its specific activity was only about $10 \%$ that of the partially purified commercial lipase toward either stearoyl-CoA or eicosatrienoy l-CoA Add1tion of free $\operatorname{CoA}, \beta$-mercaptoethanol or dithiothreitol to the assay system gave instantaneous absorbance increases in the presence or absence of the enzyme The rate of release of $\mathrm{CoA}$ from the thiol ester was a linear function of the amount of lipase present from o to $100 \mu \mathrm{g}$ when either $9 \mathrm{I} \mu \mathrm{M}$ lauroyl-CoA or $8 \mathrm{I} \mu \mathrm{M}$ arachidonoyl-CoA were used as substrate

Fig 2 shows the total amount of CoA released zersus the volume of acyl-CoA solution added It can be seen that the response was linear up to 80 nmoles The deviation from linearity above this point was also seen when free CoA was added Thus it cannot be related to the nature of the enzyme interaction with the acyl groups and mav reflect a limiting absorbance in the instrument used Only those experiments in which the change in absorbance was less than I I were considered reliable for quan- 

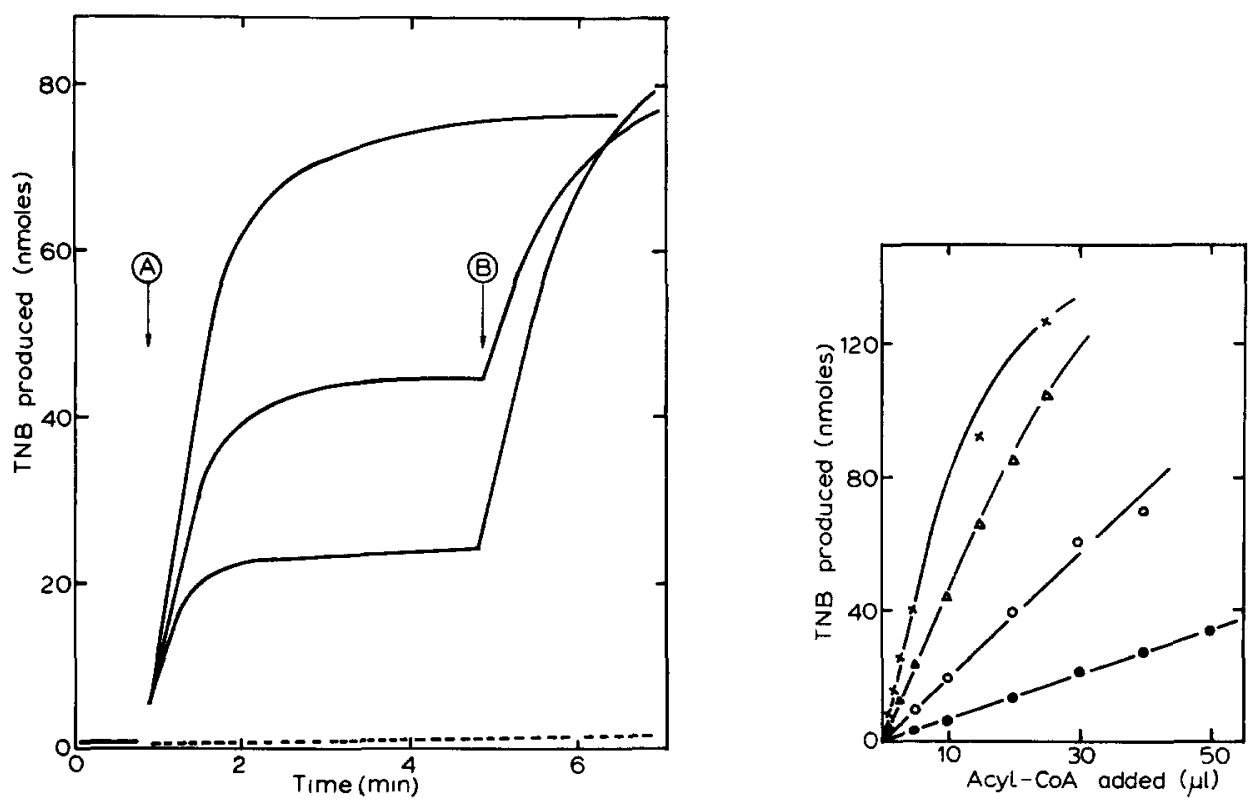

Fig I Spectrophotometric traces seen when o, 5, io and I5 $\mu$ l of a solution of eicosanoyl-CoA are added to Cuvettes I, 2, 3 and 4 respectively (Point A) containing the standard assay components described under METHODS and $\mathrm{I} o \mathrm{mg}$ of pancreatic lipase At Point B, I5 and io $\mu 1$ of eicosanoyl-CoA are added to Cuvettes 2 and 3, respectively Experiments were performed on the Gilford Model 2000 recordıng spectrophotometer at $413 \mathrm{~nm}$ with full scale absorbance $\epsilon q u$ al to I 36

Fig 2 The final amount of CoA released is plotted as a function of the volumes of various Co 1 solutions added The values were obtained from experiments such as those shown in Fig I using

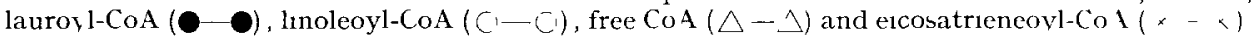

titative assays and used in subsequent calculations The concentration of the acyl$\mathrm{CoA}$ in the solutions was then calculated from the average of several determinations at differing levels such as those shown in Figs $I$ and 2

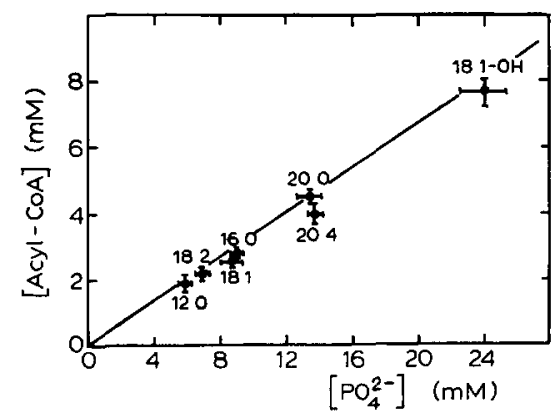

Fig 3 A comparison of the results obtained using the lipase assay method with those obtained by phosphate analysis of the same solutions of acyl-CoA The horizontal and vertical bars indicate the observed standard deviations for both assays Phosphate analyses ${ }^{10}$ were performed in tri. plicate while the lipase assays represent averages of 3-9 determinations The line represents the expected molar ratio of phosphate to thiol ester groups The nature of the acyl group is indicated for each point 
A comparison of the results obtained from the lipase assay method with those obtained by a series of phosphate analyses of the same solutions is presented in Fig 3 The expected molar ratio of 3 I for phosphate to acyl-thiol ester was obtained in each case within experimental error Thus the lipase assay system gives valid and useful results with a variety of long chain acvl-CoA substrates

\section{Kinetic properties of the lipase system}

All of the long chain acyl-CoA's tested (12-22 carbon atoms, $0-6$ double bonds served as substrates for the pancreatic lipase "hydrolase, activity and hence could be assayed by this method However, it was noticed that the rate of CoA release is dependent not only on the concentration of acyl-CoA but also upon the nature of the acyl morety We therefore decided to investigate more closely the effect of the acyl group on the reaction rate Accordingly, the initial velocity of CoA release was determined at 5 or 6 concentrations of each acyl-CoA The $K_{m}$ and $V^{r}$ values were estimated from plots of reciprocal initial velocity iersis reciprocal substrate concentration The relationship was linear in each case and no inhibition by high concentrations of acy 1 CoA was noted Such inhibition has been seen with several acyl-CoA phospholipid acyltransferases ${ }^{11,12}$ and with rat-liver acyl-CoA hydrolase ${ }^{12}$ The resulting kinetic parameters for various acyl-CoA's are given in Table I Some variation of the $I^{r}$ valuen was noticed for preparations which had been stored for various times, although the $K_{m}$ values were not dependent on the length of storage The results presented in Table I were all obtained with freshly prepared solutions of the lipase It should be noted that acetyl-CoA and malonyl-CoA were found to be inactive with this enzyme preparation It should also be pointed out that a plot of $\log K_{m}$ i' is $^{\prime}$ is chain length for the series of fully saturated acyl-CoA's is linear, indicating a possible thermodynamic relationshıp betw een chain length and apparent effectiveness as a substrate

\section{TABLE I}

KINETIC PARAMETERS FOR VARIOUS ACYL-COA'S

These parameters were obtained as described in the text Maximal velocities are given per mg of pancreatic lipase protein added

\begin{tabular}{|c|c|c|}
\hline Acyl-Co.4 & I (nmolesimin per mg) & $\Lambda_{m}(\mu M)$ \\
\hline Acetyl & $\because 10$ & - \\
\hline Nalony1 & I $O$ & - \\
\hline 120 & 90 & 600 \\
\hline $\mathrm{I}_{4} \mathrm{O}$ & $75^{\circ}$ & 80 \\
\hline I6 0 & 250 & 30 \\
\hline 180 & I do & I7 \\
\hline 200 & 20 & 8 \\
\hline I8 I $(n-9)$ & 250 & 30 \\
\hline I $82(n-6)$ & $45^{\circ}$ & I 5 \\
\hline 20 I $(n-9)$ & 400 & 200 \\
\hline $202(n-9)$ & 400 & 30 \\
\hline $203(n-6)$ & 500 & 25 \\
\hline $204(n-6)$ & I 00 & 200 \\
\hline $205(n-3)$ & 80 & - \\
\hline $226(n-3)$ & 125 & IOO \\
\hline
\end{tabular}

Brochrm Brophys Acta, 250 (1971) 36I-366 


\section{DISCUSSION}

The pancreatic lipase preparation has proved to be a convenient, and thereby valuable, tool for measuring the concentration of acyl-CoA in solutions Although we have used the method with purified synthetic acyl-CoA substrates it could, in principle, be used in the measurement of acyl-CoA contents in reaction mixtures or perhaps in biological fluids ${ }^{14-16}$ We have found the method especially useful for the assay of solutions of polyunsaturated acyl-CoA's to which antioxidants have been added for protection during storage The latter compounds preclude using the convenient assay absorption at $232 \mathrm{~nm}$ and $260 \mathrm{~nm}$ which reflect the presence of the thiol ester and adenine groups, respectively $y^{5}$ Although the sensitivity of the lipaseDTNB method is not as great as some techniques avalable for the measurement of free $\mathrm{CoA}$ (ref I4-I8) the commercial avalability of the enzyme and the stability of the necessary reagents can make it a very useful tool

The acyl-CoA hydrolase activity of pancreas resembles many liver acyl-transferases and hydrolases ${ }^{\mathbf{1 9}}$ in that it is not inhibited by the presence of DTNB This result suggests that enzymic thiol groups may not be involved in the hydrolytic mechanism Such a conclusion could not be made for the acyl-glutathone tholesterase from mouse liver which is strongly inhibited by thiol reagents such as p-chloromercuribenzoate ${ }^{20}$

The $V$ values of the hydrolase toward saturated acyl-CoA thiol esters decrease in the order I4 $0, \mathrm{I} 60, \mathrm{I} 8 \mathrm{o}, \mathrm{I} 2 \mathrm{o,} 20 \mathrm{o}$ Esters of I4-I 8 carbons are clearly preferred over shorter and longer chains This specificity is very similar to that reported for a palmitoyl thioesterase from $E \operatorname{col}^{6}$, and similar also to the specificity of rat liver acyl-CoA hydrolase reported by BARDEN AND CLELAND ${ }^{12}$ except that in the latter case palmitoyl-CoA was hydrolysed at almost ten times the rate of other saturated acyl-CoA's

Although it is not possible for us to identify the enzyme(s) responsible for the observed hydrolysis of acyl-CoA's, it is interesting to compare the acyl speciflcity of this system with that of pancreatic triglyceride lipase This enzyme, known to be in high concentration in the preparations used in this study, cleaves triglycerides and produces monoglycerıdes, diglycerıdes and fatty acıds Lauroyl, myristoyl, palmitoyl and stearoyl as well as oleoyl and linoleoyl groups are removed at about the same rate by triglyceride lipase whereas acetyl groups are cleaved at only $20 \%$ the rate of the others $^{7}$ Certain long-chain polyunsaturated fatty acyl groups (e $g 205$ and 226 but not 22 5) are resistant to hydrolysis ${ }^{21}$ The $V$ values reported in Table I for cleavage of acyl-CoA thiol esters are only vaguely similar to the general pattern reported for acyl-glycerol (oxygen) ester cleavage by triglycerıde lipase The lack of agreement may be a function of the different micellar states of the thio and oxo derivatives tested However, pancreas also contains other "esterases" which are separable from triglyceride lipase and the activity that we observe may be due to one of these ${ }^{7}$ The answer to this question must await further purification of the ac yl-CoA hydrolase(s)

\section{ACKNOWLEDGEMENTS}

This work was supported in part by a Grant (AM-053Io) from the National Brochım Biophys Acta, 250 (197I) 36I-366 
Institutes of Health ED B is currently a post-doctoral fellow of the National Institute of Neurological Disease and Stroke, Grant No I-Fo2-NS48504

\section{REFERENCLS}

I M Dixon and E C Webb, The Enzymes, Academic Press, New York, 2nd ed, 1960, p 735

2 G RENDINA 4ND M J CoOv, J Biol Chem, 225 (1957) 523

3 E E Dekrer M J Schlesinger and M J Coon, J Brol Chem, 233 (1958) +34

+ J Gergely, P Hele and ( I Ramakrishnan, I Blol Chem, i98 (1952) 323

5 P A Srere, W Seubert ANd F Lynes Brochim Blophys Aita, 33 (I959) 3 I 3

6 L M Barnes, JR and S Wakil, $J$ Biol Chem, 243 (ig68) 2955

7 P Desnuelle and P Salary, $J$ Lipid Ris 4 (1963) 369

8 G L Dllmav, Arch Brochem Brophys, dz (1959) 70

9 W Seubert, Brochem Prep, 7 (Ig6o) 80

Io $\mathrm{H}$ Eibl and W E M Lands, Anal Brochem, 30 (I969) $5 \mathrm{I}$

i E E Hill and W E M Lands, in S Wahil Lifid Metabolssm, Academic Press, New York, 1970 p 248

i $2 \mathrm{R}$ E Barden and W W Clemand, $J$ Brol Chem, 244 (1969) 3677

I3 H Ohuyama W F 2 L Lands W W Christie and F D Gunstond I Biol Chem 244 (I969) $65 \mathrm{I} 4$

I4 $\mathrm{P}$ K TUbBs ANd P B Garland, Blochem $I$ 93 (1964) $55^{\circ}$

I5 P B Garland, D Shepherd and D W Yates Blochem I 97 (1965) $5^{87}$

I6 J B Allred 4ND D $G$ Guy, Anal Buchem 29 (1969) 293

I 7 S SKREDE AND J BREMER Fur $J$ Brochem I 4 (I970) 465

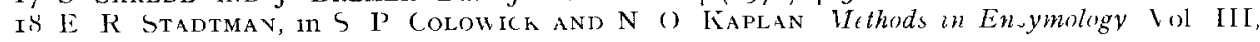
1cademic Press, New York 1957 p 931

ig W E M Lavds and P HaRT J Biol Chem, 240 (1965) 1905

$20 \mathrm{~W}$ II Kitlley and L B Bradley, $J$ Biol Chem, 206 (1954) 327

$21 \mathrm{~N}$ R Bottivo, G A Vandfviurg avd R RFiser lipids 2 (1967) frog

Brochim Brophys Acta, 250 (1971) 361-360 